\title{
Role of Fine Needle Aspiration Cytology in Evaluation of Neck Masses: Our Experience
}

\author{
${ }^{1}$ Pradipkumar Khokle, ${ }^{2}$ Sachin Garud, ${ }^{3}$ Vaibhav Jaywant Lahane, ${ }^{4}$ Swati Mishra, ${ }^{5}$ Narkhede Parag Prakash
}

\begin{abstract}
Introduction: The neck masses are relatively common problem. The differential diagnosis in a patient presenting with neck mass is often extensive and will vary with age. These neck masses are evaluated by history, clinical examination and investigation like fine needle aspiration cytology (FNAC), ultrasonography (USG), neck, computed tomography (CT) neck and excisional biopsy. Fine needle aspiration cytology is a simple, quick and cost effective method to sample superficial masses in the neck but FNAC is not substitute for histology. Study aims at the clinical spectrum of the neck masses and efficacy of FNAC in the evaluation neck masses.
\end{abstract}

Materials and methods: Prospective study including 100 cases of neck masses studied during the period of January 2012 to June 2013. Patients with acute neck space infection and nonpalpable neck masses were excluded. USG neck was done in all cases prior to FNAC examination. All surgically excised masses were sent for histopathological examination (HPE). FNAC results were compared with corresponding HPE reports.

Results: It emerges from our analysis that FNAC is $71.43 \%$ sensitive, $100 \%$ specific, and $96 \%$ accurate in diagnosing neck masses.

Conclusion: FNAC is a simple outpatient procedure for diagnosing neck masses with great sensitivity and accuracy and a complementary procedure to histopathological study.

Keywords: Fine needle aspiration cytology, Histopathological examination, Neck masses.

How to cite this article: Khokle P, Garud S, Lahane VJ, Mishra S, Prakash NP. Role of Fine Needle Aspiration Cytology in Evaluation of Neck Masses: Our Experience. Int J Otorhinolaryngol Clin 2018;10(3):99-105.

Source of support: Nil

Conflict of interest: None

\section{INTRODUCTION}

The neck masses are relatively common head and neck problem. There is often no associated symptom, other than the recognition of 'lump' noted incidentally on

\footnotetext{
${ }^{1,2}$ Assistant Professor, ${ }^{3-5}$ Junior Resident

${ }^{1,3-5}$ Department of ENT, Government Medical College and Hospital, Latur, Maharashtra, India

2Department of ENT, Shri Vasantrao Naik Government Medical College, Yavatmal, Maharashtra, India

Corresponding Author: Pradipkumar Khokle, Assistant Professor, Department of ENT, Government Medical College and Hospital, Latur, Maharashtra, India, e-mail: pdkhokle@gmail.com,
}

palpation while grooming or noticed by another individual. Five percent of all cancer patients and $12 \%$ of head and neck cancer patients will present with neck masses so it is a fairly common presenting symptom.

Two most common methods of classifying neck masses are according to the site and etiology. Neck masses may be benign or malignant. The most common neck masses are enlarged lymph nodes and thyroid nodules, parotid, and other salivary glands. Less common pathologies presenting as neck swellings are from thyroglossal cysts, branchial cleft cysts, carotid body tumors, cystic hygromas, pharyngeal pouch abnormalities and lumps of skin appendages. ${ }^{1}$ Lumps may be classified in relation to the triangles of the neck.

The differential diagnosis in a patient presenting with neck mass is often extensive and will vary with age. These neck masses are evaluated by a detail history, clinical examination and investigation like fine needle aspiration cytology (FNAC), ultrasonography (USG) neck, computed tomography (CT) neck and excisional biopsy. Clinical examination of neck has false positive result of between $20 \%$ and $30 \%$ and false-negative rate of $30-40 \%{ }^{4}$ There is no doubt that sensitivity and specificity of neck examination can be improved by radiological examination. FNAC is a simple, quick and cost-effective method to sample superficial masses in the neck. This technique is performed in the outpatient clinic, causes minimal trauma to the patient. There is no evidence suggesting that the tumor spreads through the skin track created by the fine hypodermic needle. FNAC is useful in diagnosis of salivary gland tumor where it can differentiate between a benign and malignant tumor with $90 \%$ accuracy. ${ }^{5}$ FNAC is particularly helpful in the workup of cervical masses and nodules as biopsy of cervical lymphadenopathy should not be done until all diagnostic modalities have failed to establish diagnosis. ${ }^{6}$ FNAC is not substitute for histology, especially in determination of nodal architecture in lymphoma, follicular thyroid tumors, intracapsular spread in squamous carcinoma or in the distinction of pleomorphic from monomorphic adenoma. $^{7}$

The purpose of this study is to evaluate the efficacy of FNAC in diagnosis of neck mass. It emerges from the analysis that FNAC is a safe, simple and rapid method that can be done in diagnosing wide range of neck swellings. 


\section{AIMS AND OBJECTIVES}

- To study the clinical spectrum of the neck masses.

- To study the efficacy of diagnostic test (FNAC) in the evaluation neck masses.

\section{MATERIALS AND METHODS}

Present study is the prospective, hospital-based study including 100 cases of neck masses attending ENT OPD of our hospital studied during the period of January 2012 to June 2013. Patients with acute neck space infection and nonpalpable neck masses were excluded. All patients included in study were examined and clinical history noted. USG neck was done in all cases prior to FNAC examination. FNAC were conducted in department of pathology with 21-23 gauge needle attached to the $10 \mathrm{~mL}$ plastic disposable syringe. Air dried smears were stained with hematoxylin and eosin and May-Grunwald-Giemsa stain whereas $95 \%$ ethyl alcohol fixed smears were stained by Papanicolaou stain. CT neck (plain and contrast) was done. All patients were posted for surgical excision of neck mass after proper hematological and radiological investigations. All excised specimens were sent for histopathological examination (HPE). The cytological features of all cases were reviewed with corresponding histopathology features.

\section{RESULTS}

In our study, 100 patients with neck masses were evaluated comprising of 40 males and 60 females within age group of 7-68 years. The maximum number of neck swelling were in 21-30 years age group which is $29 \%$ and minimum were in 61-70 years age group which is $3 \%$. Table 1 shows the distribution of various neck masses according to age groups. As per our study, significant difference was present gender predilection of neck swelling with thyroid swelling being common in female and salivary gland and lymph nodes swelling in males. Table 2 shows gender distribution of neck swellings. Fifty-three percent neck swelling were not associated with any complaints other than as swelling. There were $29 \%$ and $20 \%$ neck swelling with pain and dysphagia, respectively. On clinical examination, 43\% patients had midline neck swelling and rest were lateral of which $21 \%$ were submandibular. Graph 1 shows anatomical location of neck swellings. Out of 100 cases, 77 were firm, 11 soft, 5 hard and 5 were fluctuant swelling. Based on clinical and radiological examination, we found that out of 100 cases of neck masses, 40 were thyroid swelling, 28 lymph nodes swelling, 17 salivary glands swelling and 15 other neck swelling. Thyroid swelling was the most common swelling followed by lymph node swelling (Graph 2). Table 3 shows the clinical diagnosis of various neck masses. All patients were subjected to FNAC examination in department of pathology. Results of FNAC are tabulated in Table 4. All patients were posted for suitable surgery and the specimens excised were sent for HPE. The results of HPE were compared with clinical findings and more importantly with FNAC findings; the results of which are interpreted in Table 5.

Descriptive statistical analysis has been carried out in the present study. Results on continuous measurements are presented on mean SD (min-max) and results on categorical measurements are presented in number (\%). Significance is assessed at $5 \%$ level of significance. The following assumption on data is made.

Assumptions: 1. Dependent variables should be normally distributed 2. Samples drawn from the population should be random. 3. Cases of the samples should be independent. Chi-square/Fisher exact test has been used to find the significance of study parameters on categorical scale between two or more groups. Diagnostic statistics viz. sensitivity, specificity, PPV, NPV and accuracy have been computed to find the correlation of FNAC and diagnosis with HPE findings.

\section{Significant figures}

+ Suggestive significance ( $p$ value: $0.05<p<0.10$ )

* Moderately significant ( $p$ value: $0.01<p 0.05$ )

** Strongly significant ( $p$ value: 0.01 )

The statistical values of our study were as follows:

$\begin{array}{lll}\text { Sensitivity } & : & 71.43 \% \\ \text { Specificity } & : & 100 \% \\ \text { PPV } & : & 90.91 \% \\ \text { NPV } & : & 95.55 \% \\ \text { Accuracy } & : & 96 \% \\ & & p<0.001^{* *}\end{array}$

\section{DISCUSSION}

FNAC is a simple, quick and cost-effective method to sample superficial masses in the neck. This technique is performed in the outpatient clinic, causes minimal trauma to the patient. ${ }^{5}$ FNAC is particularly helpful in the workup of cervical masses and nodules as biopsy of cervical lymphadenopathy should not be done until all diagnostic modalities have failed to establish diagnosis. ${ }^{6}$ The causes for false-negative results are:

- Acellular/poorly cellular sample as encountered in large cystic papillary carcinoma, in marked desmoplasia and in cases of thick fibrous or calcified capsule.

- Sampling error-in case of salivary gland duct adenocarcinoma. 
Role of Fine Needle Aspiration Cytology in Evaluation of Neck Masses: Our Experience

Table 1: Distribution of various neck masses according to age groups

\begin{tabular}{lllllllll}
\hline & $\begin{array}{l}\text { No. of } \\
\text { thyroid } \\
\text { swelling }\end{array}$ & $\begin{array}{l}\text { No. of } \\
\text { \% of thyroid } \\
\text { swelling }\end{array}$ & $\begin{array}{l}\text { \% of } \\
\text { gland } \\
\text { swelling }\end{array}$ & $\begin{array}{l}\text { salivary } \\
\text { gland } \\
\text { swelling }\end{array}$ & $\begin{array}{l}\text { No. of } \\
\text { lymph node } \\
\text { swelling }\end{array}$ & $\begin{array}{l}\text { \% of lymph } \\
\text { node } \\
\text { swelling }\end{array}$ & $\begin{array}{l}\text { No. of other } \\
\text { swelling }\end{array}$ & $\begin{array}{l}\text { \% of other } \\
\text { swelling }\end{array}$ \\
\hline $1-10$ & 0 & 0 & 0 & 0 & 4 & 14 & 3 & 20 \\
$10-20$ & 3 & 7.5 & 6 & 35 & 7 & 25 & 5 & 33 \\
$21-30$ & 16 & 40 & 2 & 12 & 7 & 25 & 4 & 27 \\
$31-40$ & 13 & 32.5 & 1 & 6 & 3 & 11 & 1 & 7 \\
$41-50$ & 6 & 15 & 4 & 23 & 2 & 7 & 0 & 0 \\
$51-60$ & 2 & 5 & 3 & 18 & 4 & 14 & 1 & 7 \\
$61-70$ & 0 & 0 & 1 & 6 & 1 & 4 & 1 & 7 \\
\hline Total & 40 & 40 & 17 & 17 & 28 & 28 & 15 & 15 \\
\hline
\end{tabular}

Table 2: Gender distribution of patients studied

\begin{tabular}{lllll}
\hline Type of swelling & No of males & \% of male & No of female & \% of female \\
\hline Thyroid swelling & 5 & 12.5 & 35 & 87.5 \\
Lymph node swelling & 18 & 64 & 10 & 36 \\
Salivary gland swelling & 11 & 65 & 6 & 35 \\
Other swelling & 6 & 40 & 9 & 60 \\
\hline Total & 40 & 40 & 60 & 60 \\
\hline
\end{tabular}

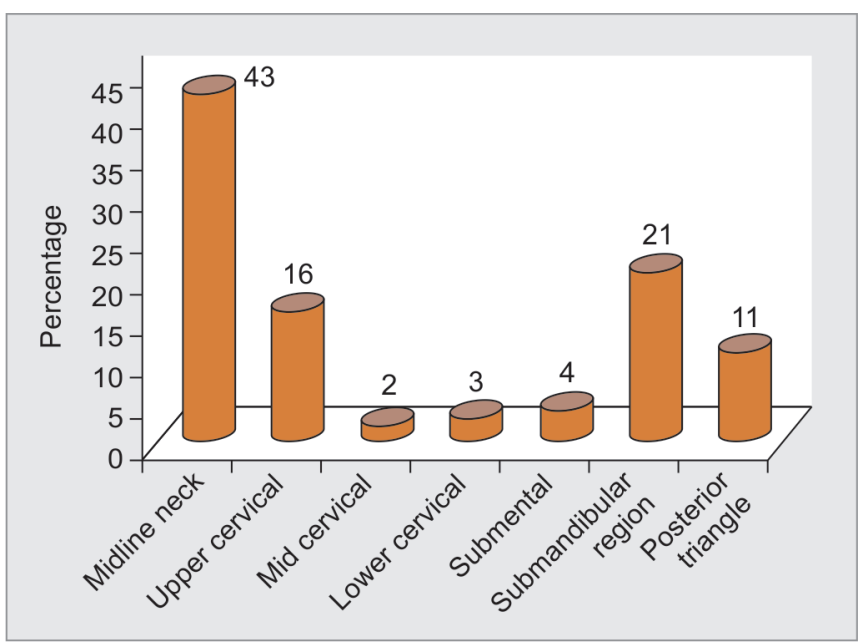

Graph 1: Anatomical site of neck swelling studied

- Thyroid carcinoma may have a macrofollicular areas and yield moderate amounts of colloid on FNAC.

When evaluating test for ability to identify patients with malignancy, the sensitivity is more important than the specificity since false negative report may encourage delay in further investigation or treatment. Needle aspiration has lower sensitivity than accuracy both in our study and in other reports. Therefore, caution is mandatory, clinical suspicion must always take precedence and so negative cytology must disregarded if there is a strong clinical suspicion. It must be borne in mind that negative result in fine needle aspiration does not rule out cancer. It cannot be over emphasized that fine needle aspiration is always a part of work up and not final diagnosis. A valuable aspect of fine needle aspiration is its ability to determine the diagnostic categorization of a mass in the neck independent of the determination of either

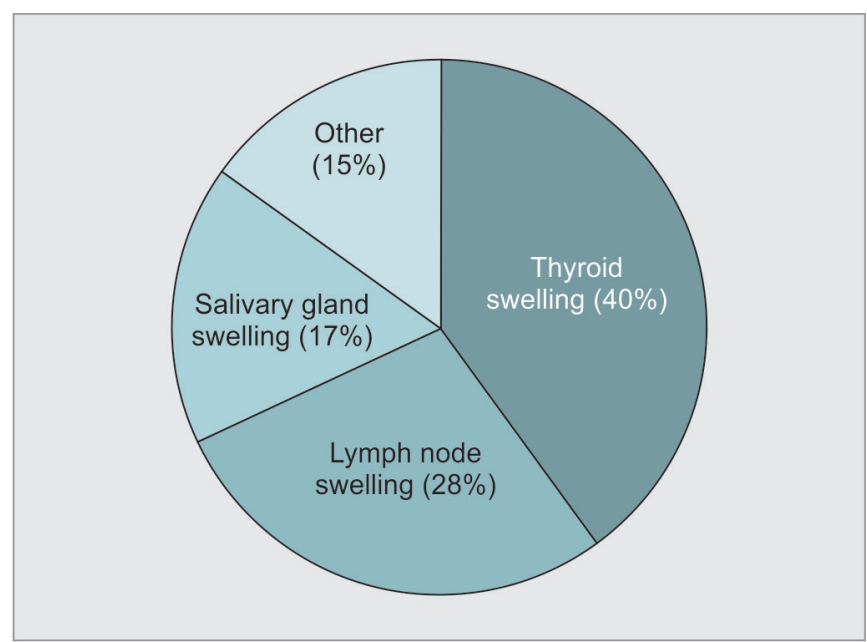

Graph 2: Types of clinically detected neck swellings

malignant or benign growth. This is particularly useful for patient presenting first time with neck mass as the only finding.

Certain limitations of the procedure in the neck region that we have encountered are:

- Difficulty in the diagnosis and sub classification of lymphomas

- Distinguishing colloid goiter from follicular adenoma.

- Differentiation of colloid goiter from macrofollicular papillary carcinoma.

- Distinguishing thyroid adenoma from early follicular carcinoma.

Our study evaluated 100 patients and found the overall sensitivity of FNAC in the diagnosis of neck masses to be $\mathbf{7 1 . 4 3} \%$ and specificity to be $\mathbf{1 0 0} \%$.

Study by Soni et al. had sensitivity of $83.01 \%$ and specificity of $78.94 \%$. Out of 59 patients, 28 were of neck 
Table 3: Clinical diagnosis of the study patients

\begin{tabular}{lll}
\hline Clinical diagnosis & Number of patients & $\%$ \\
\hline Thyroid swelling & 17 & 17 \\
Multinodular goiter & 18 & 18 \\
Colloid goiter & 3 & 3 \\
Solitary thyroid nodule & 2 & 2 \\
Thyroiditis & & \\
Salivary gland swelling & & 10 \\
Chronic sialadenitis & 10 & 6 \\
Pleomorphic adenoma & 6 & 1 \\
Malignant tumor & 1 & \\
Lymph node swelling & & 12 \\
Tb lymphadenitis & 12 & 6 \\
Reactive lymphadenitis & 6 & 4 \\
Chronic lymphadenitis & 4 & 2 \\
Lymphoma & 2 & 4 \\
Malignant metastatic & 4 & 1 \\
Other & & 1 \\
Dermoid cyst & 3 & 3 \\
Lipoma & 3 & 3 \\
Thyroglossal cyst & 1 & 1 \\
Branchial cyst & 2 & \\
Benign cystic swelling & 4 & 1 \\
Thymic cyst & 1 & 1 \\
Epidermal cyst & 1 & \\
\hline Total & 100 & \\
\hline & & \\
\hline
\end{tabular}

nodes, 14 were thyroid, 13 were of salivary gland masses and 4 were other types of neck masses; while in our study, out of 100 cases thyroid swelling were the most common (40) and lymph node swelling (28) were second most common swelling: salivary gland swelling were 17 and other swelling were 15 . As many patients of thyroid were operated and patients of lymph node swelling were not allowing biopsy and no facility of radiotherapy in our institute for metastatic lymph node. These cases were not taken into study. ${ }^{1}$

This study included patients with neck swellings presenting to the Surgical Outpatient Department of Postgraduate Medical Institute, Lady Reading Hospital Peshawar from January 2007 to December 2007 by Tariq Ahmad, Mohammad Naeem, Siddique Ahmad*, Ambreen Samad ${ }^{* *}$, Amir Nasir. Patients below 18 years of age were excluded. Patients' data were recorded. Samples of FNAC were sent to the cytologist and results recorded. The study included 50 patients with neck swellings. There were 16 male and 34 female patients with an age range of 15-55 years. In our study out of 100 case 60 were female and 40 were male. Tuberculous lymphadenitis was the commonest diagnosis (36\%) followed by reactive/nonspecific
Table 4: FNAC report of patients studied

\begin{tabular}{|c|c|c|}
\hline FNAC report & $\begin{array}{l}\text { Patients studied } \\
(n=100)\end{array}$ & $\%(n=100)$ \\
\hline \multicolumn{3}{|l|}{ Thyroid swelling } \\
\hline Multinodular goiter & 1 & 1 \\
\hline Colloid goiter & 30 & 30 \\
\hline Colloid goiter with cystic change & 4 & 4 \\
\hline Follicular carcinoma & 2 & 2 \\
\hline Lymphocytic thyroiditis & 1 & 1 \\
\hline Nodular goiter & 1 & 1 \\
\hline Papillary carcinoma & 1 & 1 \\
\hline \multicolumn{3}{|l|}{ Salivary gland swelling } \\
\hline Chronic sialadenitis & 6 & 6 \\
\hline Granulomatous sialadenitis & 1 & 1 \\
\hline Pleomorphic adenoma & 7 & 7 \\
\hline Adenoid cystic carcinoma & 1 & 1 \\
\hline Mucoepidermoid carcinoma & 1 & 1 \\
\hline \multicolumn{3}{|l|}{ Lymph node swelling } \\
\hline Tb lymphadenitis & 10 & 10 \\
\hline Reactive lymphadenitis & 8 & 8 \\
\hline Granulomatous lymph adenitis & 3 & 3 \\
\hline Malignant metastatic & 4 & 4 \\
\hline Lymphoma & 1 & 1 \\
\hline \multicolumn{3}{|l|}{ Other } \\
\hline Lipoma & 3 & 3 \\
\hline Branchial cyst & 2 & 2 \\
\hline Thyroglossal cyst & 1 & 1 \\
\hline Benign cystic lesion & 6 & 6 \\
\hline Vagal schwannoma & 1 & 1 \\
\hline Epidermal cyst & 1 & 1 \\
\hline \multicolumn{3}{|l|}{ Inconclusive FNAC } \\
\hline Bloody aspirates & 1 & 1 \\
\hline Lymphoproliferative lesion & 2 & 2 \\
\hline Inflammatory lesion & 1 & 1 \\
\hline Total & 100 & 100 \\
\hline
\end{tabular}

lymphadenitis $(18 \%)$ similar to our study. In our study, tuberculous lymphadenitis was $53.57 \%$, which is the most common lymph node swelling followed by reactive lymph node (21.43\%). Other pathologies were malignant neoplasms (14\%) similar to our study $(14 \%)$, cysts $(10 \%)$, benign neoplasms $(8 \%)$ and sialadenitis $(6 \%)$ similar to our study and inconclusive FNAC ( $8 \%)^{8}$

A retrospective study was conducted between February 2004 and August 2005 by Chauhan Setal and Rathod Dharmendra, Fine needle aspiration diagnosis was correlated with detail of relevant clinical findings and investigations. Patients between the ages of 1-80 years were taken into the study. A total of 100 patients with a head and neck swelling underwent FNAC. Out of 100 fine needle aspiration procedures, $51 \%$ were of lymph node, $20 \%$ were thyroid, $15 \%$ from salivary gland, $08 \%$ from soft tissue and $06 \%$ were miscellaneous swellings; while in our study, out of 100 neck swelling, thyroid swelling were $40 \%$, lymph node were $28 \%$, salivary 
Table 5: Correlation of clinical diagnosis, FNAC report and HPE final diagnosis

\begin{tabular}{|c|c|c|c|c|c|c|c|}
\hline & \multicolumn{3}{|c|}{ Clinical diagnosis } & \multicolumn{2}{|c|}{ FNAC report } & \multicolumn{2}{|c|}{ HPE Report } \\
\hline & No. & $\%$ & & No. & $\%$ & No. & $\%$ \\
\hline \multicolumn{8}{|l|}{ Thyroid swelling } \\
\hline Colloid goiter & 18 & 18 & & 30 & 30 & 20 & 20 \\
\hline Multinodular goiter & 17 & 17 & & 1 & 1 & 4 & 4 \\
\hline $\begin{array}{l}\text { Colloid goiter with cystic } \\
\text { change }\end{array}$ & - & - & & 4 & 4 & 4 & 4 \\
\hline Adenomatous goiter & - & - & & - & - & 1 & 1 \\
\hline Solitary thyroid nodule & 3 & 3 & & - & - & - & - \\
\hline Toxic nodular goiter & & & & 1 & 1 & 3 & 3 \\
\hline Lymphocytic thyroiditis & 2 & 2 & & 1 & 1 & 2 & 2 \\
\hline Hashimotos thyroiditis & - & - & & - & - & 2 & 2 \\
\hline Papillary carcinoma & - & - & & 1 & 1 & 3 & 3 \\
\hline Follicular carcinoma & - & - & & 2 & 2 & 1 & 1 \\
\hline \multicolumn{8}{|l|}{ Salivary gland swelling } \\
\hline Chronic sialadenitis & 10 & 10 & & 6 & 6 & 6 & 6 \\
\hline Granulomatous sialadenitis & - & - & & 1 & 1 & 1 & 1 \\
\hline Pleomorphic adenoma & 6 & 6 & & 7 & 7 & 6 & 6 \\
\hline Warthin tumor & - & - & & - & - & 1 & 1 \\
\hline Adenocarcinoma duct & - & - & & - & - & 1 & 1 \\
\hline Mucoepidermoid tumor & - & - & & 1 & 1 & 1 & 1 \\
\hline Adenoid cystic carcinoma & 1 & 1 & & 1 & 1 & 1 & 1 \\
\hline \multicolumn{8}{|l|}{ Lymph node swelling } \\
\hline TB lymphadenitis & 12 & 12 & & 10 & 10 & 15 & 15 \\
\hline Granulomatous lymphadenitis & - & - & & 3 & 3 & - & - \\
\hline Reactive lymphadenitis & 6 & 6 & & 8 & 8 & 6 & 6 \\
\hline Chronic lymphadenitis & 4 & 4 & & - & - & - & - \\
\hline Malignant metastatic & 4 & 4 & & 4 & 4 & 4 & 4 \\
\hline Non-Hodgkin lymphoma & - & - & & - & - & 2 & 2 \\
\hline Lymphoma & 2 & 2 & & 1 & 1 & 1 & 1 \\
\hline \multicolumn{8}{|l|}{ Other } \\
\hline Lipoma & 3 & 3 & & 3 & 3 & 3 & 3 \\
\hline Branchial cyst & 2 & 2 & & 2 & 2 & 2 & 2 \\
\hline Thyroglossal cyst & 1 & 1 & & 1 & 1 & 1 & 1 \\
\hline Dermoid cyst & 3 & 3 & & - & - & 4 & 4 \\
\hline Lymphangioma & - & - & & - & - & 3 & 3 \\
\hline Benign cystic lesion & 4 & 4 & & 6 & 6 & - & - \\
\hline Vagal schwannoma & - & - & & 1 & 1 & 1 & 1 \\
\hline Epidermal cyst & 1 & 1 & & 1 & 1 & 1 & 1 \\
\hline $\begin{array}{l}\text { Thymic cyst } \\
\text { Inconclusive FNAC report }\end{array}$ & 1 & 1 & & - & - & - & - \\
\hline Bloody aspirate & - & - & 1 & & 1 & - & - \\
\hline Lymphoproliferative lesion & - & - & 2 & & 2 & - & - \\
\hline Inflammatory smear & & & 1 & & 1 & - & - \\
\hline
\end{tabular}

gland swelling were $17 \%$ and other swelling were $15 \%$. Inflammatory swelling was 33\%, tuberculous lymph nodes were $(55 \%)$ and involvement is common in the age group of 21-30 years (22\%) with male preponderance $(55 \%)^{9}$ which is similar to our study. In our study tuberculous lymphadenitis were $53.57 \%$, male preponderance in lymph node swelling (64\%) and neck swelling were common in age group of 21-30 years (25\%) in lymph node swelling and 29\% in 20-30 years in all neck swelling.

Howlett, DC, et al., studied a total of 276 patients and found FNAC of neck nodes to have a sensitivity of $89 \%$ and a specificity of $57 \%$ while in our study sensitivity is $71.43 \%$ and specificity is $100 \%$, for thyroid masses, the sensitivity was $62 \%$ and specificity was $86 \%$ while in our 
Table 6: Comparison of our study with other studies for efficacy of FNAC

\begin{tabular}{llllll}
\hline & & Howlett & & Jens Thomsen, Jen.Chr. \\
& Present study & Soni et al ${ }^{1}$ & DC et al & TilakV Dhaded et al ${ }^{10}$ & Andreassen $^{13}$ \\
\hline Total number of patients & 100 & 68 & 712 & 550 & 108 \\
Duration of study & 18 months & 1 year & 1 year & 18 months & 1 year \\
Sensitivity(\%) & 71.43 & 83.01 & 89 & 90.91 & - \\
Specificity(\%) & 98.85 & 78.94 & 57 & 93.18 & - \\
Accuracy(\%) & 96 & - & - & 92.73 & 93 \\
\hline
\end{tabular}

Table 7: Comparison of our study with other studies for efficacy of FNAC

\begin{tabular}{llll}
\hline Study & Year of study & Sensitivity of FNAC & Specificity of FNAC \\
\hline Present study & $2012-13$ & $71.43(\%)$ & $98.85(\%)$ \\
E Razmpa, H Ghanati ${ }^{14}$ & 2000 & $92.3(\%)$ & $88.1(\%)$ \\
Abdulqadir M, Zangana S. ${ }^{15}$ & 2003 & $90(\%)$ & $100(\%)$ \\
\hline
\end{tabular}

study sensitivity is $75 \%$ and specificity is $97.29 \%$; and for salivary glands, the sensitivity was $64 \%$ and specificity was $100 \%$ which was similar to our study that is sensitivity of FNAC for salivary gland swelling is $66.67 \%$ and specificity is $100 \%{ }^{6}$

Tilak V, Dhaded AV, et al. studied 550 patients and found the overall sensitivity of FNAC for neck masses to be $90.91 \%$ which is greater than our study and specificity to be $93.18 \%$ which is lesser than our study. ${ }^{10}$

Khiery and Ahmed study, revealed that majority of lymph nodes were benign in origin and most common is tuberculous lymphadenitis followed by reactive lymphadenitis which is similar to our study. The calculated sensitivity rate in different studies is from 81 to $92 \%$. Specificity varies from 86 to $98.9 \%$. In our study, the sensitivity and specificity of FNAC of lymphadenopathy to diagnose tubercular lymphadenopathy were $66.67 \%$ and $100.0 \%$, respectively. ${ }^{11}$

Difference in the specificity between our study and others may be due to differences in the method of aspiration of the neck lump. In our study, blind FNAC was performed by different technicians without ultrasound guidance. In Howlett DC, et al. study, ultrasound-guided FNAC was used in 50\% of the thyroid group and a few parotid patients. The differences might also be explained by differences in the patient population. In India, most patients are illiterate and unaware of their health problems until they are at an advanced stage. The majority of patients present with a huge neck mass which is obvious and easy for the cytopathologist to locate with FNAC without the use of ultrasound guidance. In addition, in such large lesions there may well be a sampling error within the mass itself with different regions of the mass having different grades of pathology.

Finally, James Edward M et al. ${ }^{12}$ observed an overall accuracy for FNAC of $94.5 \%$ which is almost similar to our study $(96 \%)$

Comparison of our study with other studies for efficacy of FNAC is tabulated in Tables 6 and 7.

\section{CONCLUSION}

Neck swelling is the most common problem in practice Otolaryngology and FNAC offers a simple method of diagnosis of neoplastic and non-neoplastic lesions in the neck. It can be performed as an outpatient procedure. The procedure is acceptable to most of the patients. It does not require anesthesia and speedy results are available. An accurate diagnosis can be made. It is complementary procedure to HPE. It is clear that FNAC is the best investigation one can ask for with good accuracy which can be achieved with greater experience and expertise. FNAC of neck masses with clinical co relation and Ultrasonography provide most useful information to surgeon to determine the further mode of management. .It is the most accurate where there is a close cooperation between clinician, cytopathologist and radiologist. Hence, we conclude from present study, FNAC is a safe, Simple and rapid method that can be done in diagnosing wide range of neck swellings.

\section{REFERENCES}

1. Soni S, Pippal SK, Yashveer B, Srivastava P, Efficacy of fine needle aspiration in diagnosis of neck masses. World Articles of Ear Nose and Throat.

2. Beahrs OH, Barber Jr KW. The value of radical dissection of structure of the neck in the management of carcinoma of the lip, mouth and larynx. Archive Surgery 1962;85:49-56.

3. Feinmesser R, Freeman JL, Noyek AM, Birt BD. Metastatic neck diseases. Archives of Otolaryngology-Head and Neck Surgery 1987;113:1307-10.

4. Friedman M, Mafee MF, Pacella BL Jr, Strorigl TL, Dew LL, Toriumi DM. Rationale for elective neck dissection in Laryngoscope 1990;100(1):54-59.

5. Burnand KG, Young AE, Lucas J, Rolands BJ, Scholefield J. The new Aird's companion in surgical studies. 3rd edition. China: Elsevier; 2005.

6. Howlett DC, Harper B, Quante M, Berresford A, Morley M, Grant J, Ramesar K, Barnes S. Diagnostic adequacy and accuracy of fine needle aspiration cytology in neck lump assessment: results from a regional cancer network over a one year period. J Laryngol Otol. 2007 Jun; 121(6):571-579. Epub 201. 
7. Watkinson JC, Wilson JA, Gaze M, Stell PM, Maran AGD. Stell and Maran's Head and neck surgery, ButterworthHeinemann, Oxford, 4th edition, chapter 2; 200098. p. 20-21.

8. Tariq Ahmad, Mohammad Naeem, Siddique Ahmad, Ambreen Samad, Amir Nasir. Fine Needle Aspiration Cytology (FNAC) and Neck Swellings in the Surgical Outpatient. J Ayub Med Coll Abbottabad 2008;20(3).

9. Chauhan Setal, Rathod Dharmendra, FNAC of Swellings of Head and Neck Region Journal of Applied Basic Medical Sciences Year: 2011, Volume: 13B, Issue: 17 First page: (1) Last page : (6) Print ISSN : 0975-8917.

10. Vijay Tilak, A V Dhaded, Ragini Jain, Indian J Pathol Microbi ol. 2002:45(1): 23-30.
11. Khiery J, Ahmed ME. Cervical lymphadenopathy in Khartoum. J Trop Med Hyg 1992; 95(6):416-419.

12. Edward J, Young MD, et al. Needle aspiration cytologic biopsy in head and neck masses. The American Journal of Surgery. 1981 Oct;142 (4).

13. Jens Thomsen, J C Andreassen, C Bangsbo, Fine needle aspiration biopsy of tumours of head and neck. The Journal of Laryngology and Otology 1973;87:1211-1216.

14. Razmpa EH, Ghanaati B. Naghibzadeh P. Mazloom and A. Kashfi. Acta medicina Iranica The Journal of the Faculty of Medicine, Tehran University of Medical Sciences. 2002;40:3.

15. Abdulqadir M,Zangana S, Abu B, Sherwan A G. A Comparative Study Between Cytological and Histopathological Findings in Thyroid Swellings in Erbil City. Adv. in Med Dent Sci. 2009; 3(1): 29-34. 